\title{
Scanning Electron Microscopy Morphology of the Uterine Epithelium of Mares Infused with Gentamicin
}

\author{
F.K. Al-Bagdadi*, B.E. Eilts**, G.F. Richardson***, D. J. Hillmann*
}

*Departments of Comparative Biomedical Sciences and **Veterinary Clinical Science, School of Veterinary Medicine, Louisiana State University, Baton Rouge, LA 70803; ***Department of Health Management, Atlantic Veterinary College, University of Prince Edward Island, Charlottetown, P.E.I. Canada C1A4P3

Veterinarians treated bacterial endometritis in mares using prostaglandins ${ }^{1}$, infusions of antiseptics ${ }^{2}$, antibiotics $^{3}$ and Gentamicin ${ }^{4}$. The effects of repeated intrauterine infusions of povidone iodine and gentamicin on the histopathology of the endometrium have been reported..$^{4-6}$. The scanning electron microscope has been used to study the surface morphology of the uterus in human beings ${ }^{7,8}$, rabbit ${ }^{9}$, mares ${ }^{10}$, and rats ${ }^{11}$. The purpose of this scanning electron microscopic study was to examine, if repeated intrauterine infusion of mares with gentamicin or with saline alone would change the surface morphology of the mares' uterine epithelium.

Five yearling thoroughbred mares were infused with $40 \mathrm{ml}$ gentamicin, $(50 \mathrm{mg} / \mathrm{ml})$ mixed with $80 \mathrm{ml}$ of normal saline ( $120 \mathrm{ml}$ total infusion) on 2 consecutive days. Four control mares received intrauterine infusions of $120 \mathrm{ml}$ of normal saline on 2 consecutive days. Endometrial biopsies were obtained from each mare 3 days after the second infusion. A piece was cut from each biopsy and washed in normal saline and fixed in a combination of $1.25 \%$ glutaraldehyde and $2 \%$ formaldehyde in $0.1 \mathrm{M}$ phosphate buffer $(\mathrm{pH} 7.4)$ for two hours. They were postfixed for one hour in $1 \%$ osmium tetroxide, washed in the same buffer with 5\% sucrose, dehydrated in graded percentages of alcohol and dried in a Polaron critical point dryer in liquid $\mathrm{CO}_{2}$. The dried pieces were then mounted on aluminum stubs with double-sided adhesive tape and sputter coated with gold-palladium (60:40) for 4-8 minutes in a Hummer V sputter coater. The specimens were examined using a Cambridge S-150, scanning electron microscope, operated at $20 \mathrm{KV}$. inutes. The images of the secondary scattered electrons from the examined specimens were photographed using 4 X5 Polaroid $^{\circledR}$ film.

The gentamicin infusion caused changes in the endometrial epithelium of the examined biopsies which were not seen in the normal saline infused group (Fig 1). Numerous endometrial secretory cells had an abundance of apical surface perforations. The apical membrane portion of many secretory cells broke down or sloughed off (Fig 2). The perforated, sloughed-off epithelium extended over a large area of the endometrium.

The greatest morphological changes induced by gentamicin in this study were seen in the secretory cells. Similar changes have also been observed in $\operatorname{cows}^{12}$, and humans ${ }^{6,8}$. This study indicates that the repeated gentamicin infusions destroyed a considerable number of endometrial apical surfaces. We suggest that this study, with its preliminary data, provides interest for further investigations into the effect of repeated intrauterine infusion of gentamicin on the endometrial mucosa of mares.

\section{References}

[1] B.K. Gustafson et al., Compen. on Contin. Edu. for the Pract. Vet. 3.4 (1981) 105 -109.

[2] T.L. Blanchard et al., Compen. on Contin. Edu. for the Pract. Vet. 2. 9 (1980) S141-S148. 
[3] P. Lieux, Wheaton: American Veterinary Publications, Inc. (1972) 597-654.

[4] J.W. Houdeshell et al., VM/SAC. 67 (1972) 1348-1352.

[5] B.E. Eilts et al., Theriogenology. 29, 6 (1988) 253-1259.

[6] L.M. Olsen et al., Theriogenology. 37 (1992) 1311-1325.

[7] S. D’Aquino et al., Archive di Ostetricia e Gynecology. 75 (1970) 267-282.

[8] E. Johannisson et al., Fertility and Sterility. 2 (1972) 3, 613-625.

[9] H. Kanagawa et al., Anatomical Record. 174 (1972) 205-226.

[10] C.A. Samuel et al., J. Reprod. Fert. Suppl. (1979) 287-292.

[11] J.S. Sanfilippo et al., Surgery, Gynecology and Obstetrics. 16 (1985) 421-428.

[12] Y.A. Kojima et al., Zellforsch Mikrosk Z 104 (1970) 69-86.

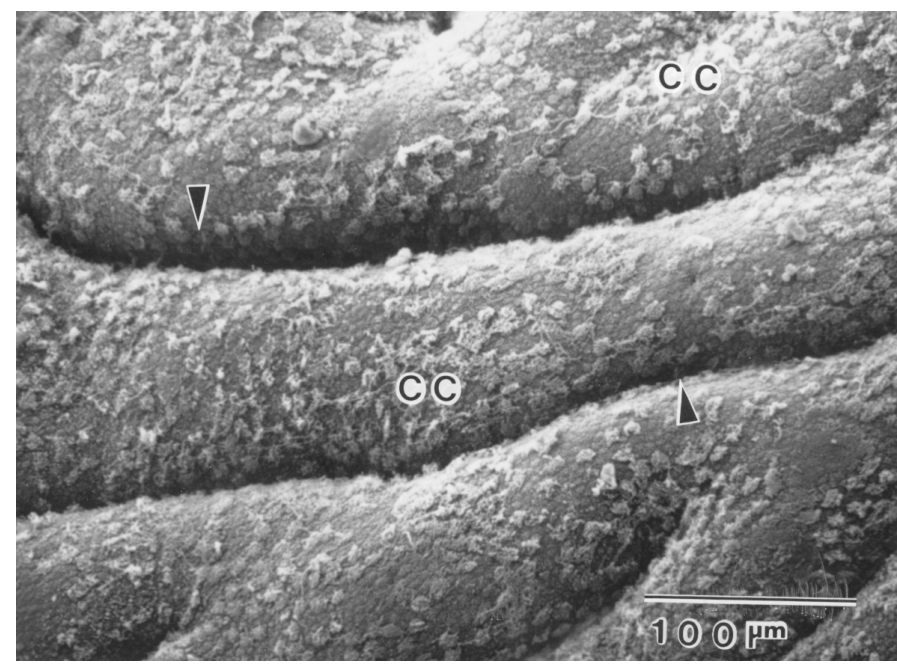

FIG. 1. Scanning electron micrograph of the uterine epithelium of a control mare showing longitudinal folds separated by longitudinal troughs (arrows). The endometrial mucosa is covered with abundant ciliated cells (CC).

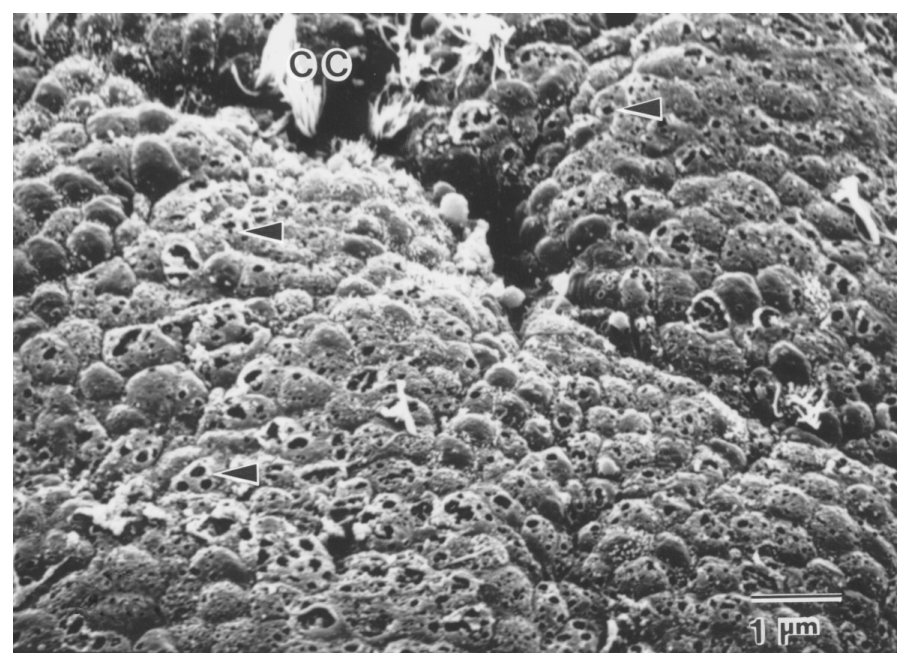

FIG. 2. Scanning electron micrograph of the uterine epithelium of a mare that had been infused with gentamicin. Almost all the epithelium shows perforations and cavities (arrow heads). The apical part of many epithelial cells is sloughed off. Several ciliated cells (CC) have short cilia. 